\title{
Exploring the Eco-Efficiency of Transport-Related Particulate Matter Pollution in Nairobi City, Kenya
}

\author{
Alfred Kipchumba Muge ${ }^{1^{*}}$, Qian Jia1, Ying Wang1, Fengting Li $^{1,2^{*}}$ \\ ${ }^{1}$ State Key Laboratory of Pollution Control and Resources Reuse, College of Environmental Science and Engineering, Tongji \\ University, Shanghai, China \\ ${ }^{2}$ Shanghai Institute of Pollution Control and Ecological Security, Shanghai, China \\ Email: *alfredmuge@tongji.edu.cn, jiaqian@tongji.edu.cn, yingwang@tongji.edu.cn, ^fengting@tongji.edu.cn
}

How to cite this paper: Muge, A.K., Jia, Q., Wang, Y. and Li, F.T. (2020) Exploring the Eco-Efficiency of Transport-Related Particulate Matter Pollution in Nairobi City, Kenya. Open Access Library Journal, 7: e7067.

https://doi.org/10.4236/oalib.1107067

Received: December 7, 2020

Accepted: December 28, 2020

Published: December 31, 2020

Copyright $\odot 2020$ by author(s) and Open Access Library Inc.

This work is licensed under the Creative Commons Attribution International License (CC BY 4.0).

http://creativecommons.org/licenses/by/4.0/

\section{(c) (i) Open Access}

\begin{abstract}
Eco-efficiency of the transport sector is a novel idea of high importance for reduced environmental pollution and sound resource use in Nairobi City. An assessment of transport eco-efficiency of the 11 sub-counties of the city was carried out for the period between June 2019 and May 2020 by examining the overall transport eco-efficiency levels, specific sub-regional variability in the efficiency and factors affecting efficiency. To realize this, a combined PCA-DEA-MLR approach is applied. The empirical results of the study indicate that the overall transport eco-efficiency of the 11 sub-counties is 0.67 , with only Makadara sub-county being optimally efficient while most being moderately efficient to highly inefficient. This result indicates that the development of the transport sector in the city significantly harms the environment and human well-being. The findings also show that the amount of wage and number of employees had a noteworthy positive impact on transport eco-efficiency while fuel consumption, traffic volume, transport share of the Gross County Product (GCP) and transport attributed particulate matter pollution had a notable negative impact on transport eco-efficiency of sub-counties in the city. Several factors that affect transport eco-efficiency were noted and recommendations made for enhancing the transport eco-efficiency thus higher quality of life for Nairobi City residents and overall sustainable development.
\end{abstract}

\section{Subject Areas}

Environmental Monitoring and Assessment 


\section{Keywords}

Eco-Efficiency, Transport Sector, Particulate Matter, Air Pollution, City

\section{Introduction}

Over the past few years, Nairobi City has been a thriving metropolis with significant economic growth that has made it an influential financial and commercial regional hub. Urban transport plays a pivotal role in the economy of the city and accounts for a major share of the gross county product $(\mathrm{GCP})^{1}$. However, traffic-related pollution is the largest contributor to particulate matter air pollution in the city [1] [2]. Traffic emissions mainly impact air quality in the city with high airborne black carbon concentrations measured near roadways [3]. Imported vehicles in the city were reported to have $2-3$ times worse fuel economy than from the countries of origin [4]. This is mainly because $97 \%$ of the new fleet of vehicles are used vehicles imported majorly from Japan [5]. In this study, Nairobi City was chosen since it accounts for the largest portion of the country's per capita real GDP and has a unique social-economic setup. Eco-efficiency as an important sustainability analysis tool was selected to explore the empirical relationship existing between environmental cost and environmental impact of economic activities from the transport sector in the city.

Over the years, eco-efficiency has been applied in many fields by different scholars and researchers such as industry [6] [7] [8], tourism [9], enterprises [10], waste treatment [11] [12], regions [13] and cities [14] [15] [16]. In cities, applying the principles of eco-efficiency has focused more on aspects of urbanization, urban clustering, residential development and government transparency. Some studies have explored transport eco-efficiency in entire countries [17] [18] [19] while only a few examining transport eco-efficiency in cities such as an analysis of the transport eco-efficiency scenarios to support sustainability assessment in Dhaka City, Bangladesh [20] and an estimation of impacts from transport-related emissions and evaluation of the associated social cost in Chengdu City, China [21]. Little attention has been paid to examining eco-efficiency of the transport sector using DEA. Further, none of the studies focused on factors influencing transport eco-efficiency. Thus, this study could serve as a basis for understanding the environmental impact of the transport sector based on eco-efficiency measurement of PM pollution.

Evaluating eco-efficiency can be done using several methods such as life-cycle assessment [22] [23], index system method or ratio method [24] [25] [26], data envelopment method (DEA) [15] [27], ecological footprint method [28] [29] and the stochastic frontier method [30]. Over the years, the most preferable method for eco-efficiency measurement has been the DEA model which is based on rela${ }^{1}$ Gross County Product (GCP) is a geographic breakdown of Kenya's Gross Domestic Product (GDP) that gives an estimate of the size and structure of county economies. In the context of this study, GCP refers to the GCP of Nairobi County. 
tive efficiency using different return to scales, and the possibility of multiple inputs and multiple outputs [31]. The traditional DEA model is unsuitable for ranking several DMUs hence the development of the slack-based model [32] which was modified to the super-efficiency model [33]. For city eco-efficiency determination, the choice of indicators has ranged from water, energy, labor and capital as inputs; GDP as desired output to water, air, and land pollution as undesired outputs [29] [34] [35] [36] [37] [38]. An application of the slack-based measurement data envelopment analysis (SBM-DEA) to determine the environmental efficiency of the U.S. transport sector adopted gross domestic product (GDP) is a measure of the overall economic output of the sector and $\mathrm{CO}_{2}$ as an undesirable output [18]. An extended DEA was used to determine the eco-efficiency of the transport sector in China incorporated traffic accidents and $\mathrm{CO}_{2}$ emissions as variables in estimating inefficiencies in the transport sector [19]. Despite the DEA model being useful in eco-efficiency evaluation, the application is limited due to the mutual interference between indicators [39]. Further, concerning transport eco-efficiency, environmental indicators need to be apportioned as per the sources/contributors before DEA modelling. To overcome these challenges, PCA is used to evaluate transport eco-efficiency. PCA transforms data into weighted linear combinations accounting for the majority of the variance of the dataset [40]. PCA helped to quantify the sources of air pollution by segregating interrelationships into independent components by ensuring the correlation and comparison of PM and its components to meteorological parameters [41]. PCA is advantageous since it can determine the optimum number of sampling parameters in a certain area even without a field visit [42].

By applying multiple regression (MLR), the effects of each parameter and their correlations can be evaluated [43]. This study also investigates the influence of several factors on transport eco-efficiency. MLR is one of the most commonly used methods for identifying the dependence of a response variable on several independent (predictor) variables [44]. Therefore, a three-pronged approach is proposed here that contains processing transport-related parameters by PCA, assessing the environmental performance of the transport sector by DEA and evaluating influencing factors of eco-efficiency by MLR. Measuring and understanding the eco-efficiency of PM air pollution resulting from the transport sector in Nairobi City would help to increase the knowledge base that is urgently required to aid in better policies and regulations geared at decreasing harmful transport emissions. To realize this goal, this study applies an integrated approach of PCA, DEA and MLR to evaluate the transport eco-efficiency in the city. We attempt to go a step further by incorporating sustainability aspects in the selection of indicators to inform eco-efficiency measurement. It is hypothesized that the degree of eco-efficiency of PM pollution varies significantly due to influence from the transport sector, the transport source of PM pollution is the major contributor to the state of air quality and different parameters have noteworthy influence on eco-efficiency of transport-related PM pollution. For the analysis, we use publicly available data for the period between June 2019 and 
May 2020. No prior information or expert judgement was used in the analysis.

The purpose of this research is to determine the degree of eco-efficiency of particulate matter (PM) air pollution resulting from the transport sector in Nairobi City, Kenya by identifying sources of particulate matter, determining the transport eco-efficiency and assessing the influence of different parameters to the transport eco-efficiency.

In the rest of this study, we detail the materials and methods used in Section 2. We then report and discuss the results in Section 3. Finally, we give conclusions and recommendations in Section 4.

\section{Materials and Methods}

\subsection{Study Area}

Nairobi is the capital city of Kenya with an area of about $700 \mathrm{~km}^{2}$ and an estimated population of about 4 million people as of 2019 with a projected figure of 6 million by 2025 [45]. The city is among the 47 counties within the country. The study was conducted based on the 11 sub-counties of the city: Dagoretti, Embakasi, Kamukunji, Kasarani, Kibra, Lang'ata, Makadara, Mathare, Njiru, Starehe and Westlands.

\subsection{Data}

Eco-efficiency measurement is pegged on the selection of suitable indicators as the basis for more precise and tailored measurement. More specifically, the DEA model for eco-efficiency analysis of cities requires the selection of suitable indicators based on existing statistical systems and data availability for more tailored and specific needs of cities. Suitable eco-efficiency indicators are either social, economic or environmental. Economic and environmental indicators are easily quantifiable while social indicators are less easily quantifiable hence are fewer in number [34]. Variations in eco-efficiency levels of the transport sector can be captured by several variables or indicators. These indicators can be broadly divided into two categories: input indicators and output indicators. Input indicators are the independent variables and capture the resource and capital input to the transport sector while output indicators are the dependent variables and describe the consequences from the sector.

Previous studies indicate that the eco-efficiency of different sectors within a country, territory or city can be measured based on how data is utilized. Measurement of eco-efficiency is based on the environmental cost in terms of pollution emissions, resources used and cost of the environmental burden against economic output in terms of value-added of benefit, unit of product or service and cost associated with an environmental burden [46]. In this study, the environmental cost and environmental burden aspects were used to categorize variables as outputs and inputs. The input variables included fuel consumption, number of employees and trips per day. The output variables included GCP share of the transport sector, average monthly wages, $\mathrm{PM}_{2.5}$ pollution, $\mathrm{PM}_{10}$ pol- 
lution, $\mathrm{SO}_{2}$ emissions, $\mathrm{CO}$ emissions, $\mathrm{NO}_{2}$ emissions and $\mathrm{O}_{3}$ emissions. Table 1 summarizes the sources of the air quality, meteorological, economic and resource consumption data.

\subsection{Methods}

The study adopted a conceptual framework that took into consideration the concept of eco-efficiency as measured by making use of parameters such as environmental pollution, resource use, employment, traffic volume, economic gains and wage situation. The conceptual framework for this study is illustrated in Figure 1. To determine the eco-efficiency of transport-related PM air pollution, first, a suitable eco-efficiency index system is constructed based on the above-mentioned parameters. Second, a principal component analysis is conducted for environmental pollution and meteorological parameters to extract and categorize principal components thus isolating the ones attributed to traffic sources. Third, data envelopment analysis is run for the resulting transport attributed principal component alongside wage situation and economic gains as output indicators and resource use, employment and traffic volumes as to the input indicators. Fourth, the results from the DEA modelling alongside other factors were analyzed to explore their relationships with transport eco-efficiency. Last, the conclusions are drawn and suggestions given can help to improve transport eco-efficiency in Nairobi City.

Table 1. Summary of the data sources and characteristics.

\begin{tabular}{|c|c|c|c|c|c|}
\hline Data Type & Data Source & $\begin{array}{c}\text { Mode of } \\
\text { Measurement }\end{array}$ & Pollutant/Parameter & $\begin{array}{l}\text { Monitoring } \\
\text { Stations }\end{array}$ & $\begin{array}{l}\text { Monitoring } \\
\text { Frequency }\end{array}$ \\
\hline \multirow{3}{*}{$\begin{array}{l}\text { Air Quality } \\
\text { Data }\end{array}$} & Code-for-Africa [47] & $\begin{array}{l}\text { Optical sensors } \\
\text { SDS011 PMS5003 }\end{array}$ & $\mathrm{PM}_{2.5}, \mathrm{PM}_{10}$ & 41 stations & Hourly \\
\hline & MIT-Senseable-City-Lab [48] & $\begin{array}{l}\text { Electrochemical } \\
\text { gas sensors }\end{array}$ & $\begin{array}{l}\mathrm{PM}_{2.5}, \mathrm{PM}_{10} \\
\mathrm{SO}_{2}, \mathrm{NO}_{2}, \mathrm{NO}\end{array}$ & 5 stations & Hourly \\
\hline & OpenAQ/US-EPA [49] & Optical sensors & $\mathrm{PM}_{2.5}$ & 2 stations & Hourly \\
\hline \multirow{2}{*}{$\begin{array}{l}\text { Meteorological } \\
\text { Data }\end{array}$} & Code-for-Africa [47] & $\begin{array}{l}\text { Optical sensors } \\
\text { DHT22 }\end{array}$ & $\begin{array}{l}\text { Humidity, } \\
\text { Temperature }\end{array}$ & 8 stations & Hourly \\
\hline & $\begin{array}{l}\text { Kenya-Meteorological-Department } \\
{[50]}\end{array}$ & $\begin{array}{l}\text { Weather monitoring } \\
\text { instruments }\end{array}$ & $\begin{array}{c}\text { Rainfall amounts, } \\
\text { solar radiation, } \\
\text { wind direction, wind speed }\end{array}$ & 4 stations & Daily \\
\hline \multirow{4}{*}{ Economic data } & $\begin{array}{c}\text { Kenya-National-Bureau-of-Statistics } \\
{[51]}\end{array}$ & Economic Survey & Transport share of GCP & Per sub-county & Monthly \\
\hline & Central-Bank-of-Kenya [52] & Economic Survey & Total GCP & Per sub-county & Monthly \\
\hline & $\begin{array}{c}\text { Kenya-National-Bureau-of-Statistics } \\
{[51]}\end{array}$ & Economic Survey & Average monthly wage & Per sub-county & Monthly \\
\hline & Nairobi-City-County [53] & Transport Survey & Traffic volume & Per sub-county & Monthly \\
\hline $\begin{array}{c}\text { Resource } \\
\text { Consumption }\end{array}$ & $\begin{array}{c}\text { Kenya-National-Bureau-of-Statistics } \\
{[51]}\end{array}$ & Transport Survey & $\begin{array}{l}\text { Petrol and diesel } \\
\text { consumption for vehicles }\end{array}$ & Per sub-county & Monthly \\
\hline
\end{tabular}




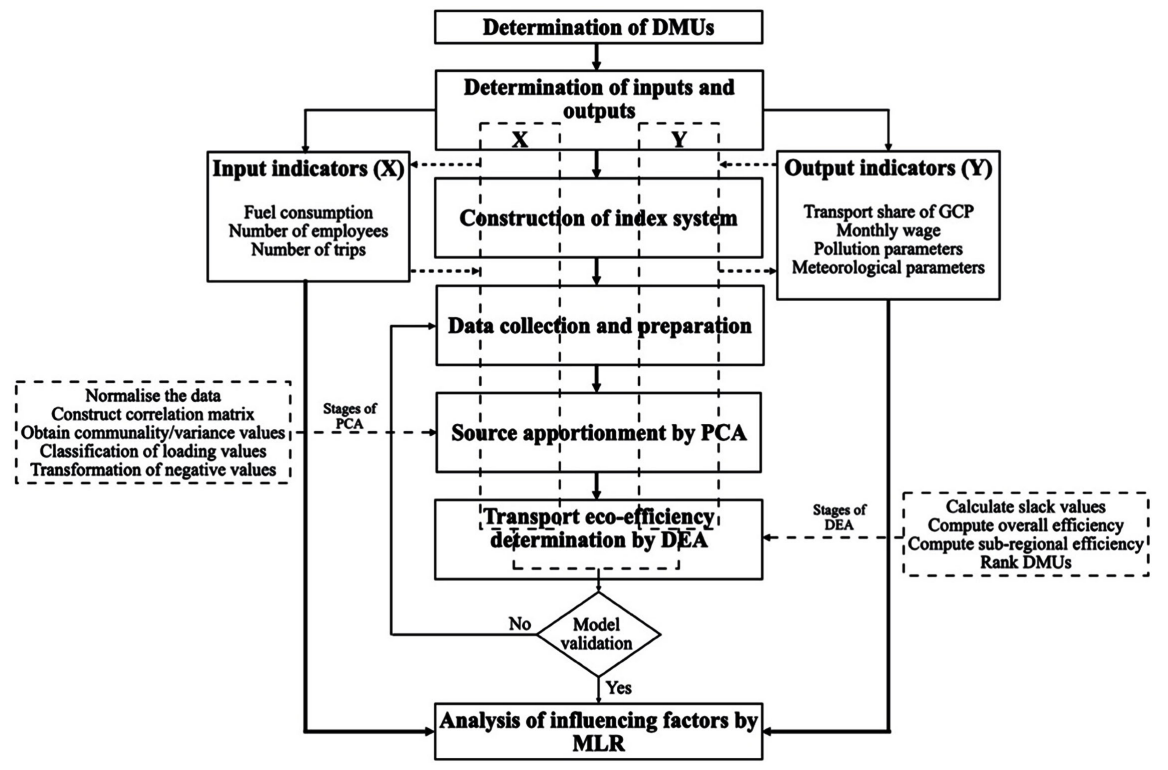

Figure 1. The conceptual framework for this present study.

\subsubsection{Selection of Variables (Indicators)}

The suitable establishment of the input and output variables is a vital step of the analysis of the relative efficiency of Decision-Making Units (DMUs) when undertaking DEA. The number of variables chosen was arrived at to avoid redundancy and a shift towards the eco-efficiency frontier [54]. As seen in Table 2, a pertinent number and nature of inputs and outputs were identified to help determine and describe the eco-efficiency of transport-related particulate matter pollution in Nairobi City. The independent input variables are fuel consumption, the number of employees and trips per day. The dependent (undesirable) output variables are $\mathrm{PM}_{2.5}$ pollution, $\mathrm{PM}_{10}$ pollution, $\mathrm{SO}_{2}$ emissions, $\mathrm{CO}$ emissions, $\mathrm{NO}_{2}$ emissions and $\mathrm{O}_{3}$ emissions. The dependent (desirable) output variables are GCP share of the transport sector and average monthly wage. The difference between the maximum and minimum values was relatively large for most values of the indicators. The difference was, however, the largest for trips per day and the smallest for temperature.

\subsubsection{Principal Component Analysis (PCA)}

The PCA model [55] [56] adopted for this study was:

$$
P C_{i}=l_{1 i} X_{i}+l_{2 i} X_{2}+\cdots+l_{n i} X_{n}
$$

subject to

$$
\operatorname{Var}\left(P C_{i}\right)=\max \text {, and } \sum_{j=1}^{m} l_{j i}^{2}=1
$$

where $P C_{i}$ is the principal component, the $i$ th is the principal component and $X_{i}$ is the loading of the observed variable $X_{i}$.

The parameters that were subjected to PCA were environmental pollution $\left(\mathrm{PM}_{2.5}, \mathrm{PM}_{10}, \mathrm{CO}, \mathrm{NO}_{2}, \mathrm{SO}_{2}, \mathrm{O}_{3}\right)$ and meteorological situation (rainfall, relative humidity, temperature, solar radiation, wind speed and wind direction). 
Table 2. Summary of the chosen inputs and output indicators.

\begin{tabular}{|c|c|c|c|}
\hline Variable & Category & Indicator & Units \\
\hline \multirow{9}{*}{$\begin{array}{l}\text { Independent } \\
\text { Input Variable }\end{array}$} & Resource use & Fuel consumption & Metric tonnes \\
\hline & Employment & Number of employed persons & Numbers \\
\hline & Traffic volume & Trips per day & Numbers \\
\hline & \multirow{6}{*}{$\begin{array}{l}\text { Meteorological } \\
\text { situation }\end{array}$} & Rainfall & $\mathrm{mm}$ \\
\hline & & Relative Humidity & $\%$ \\
\hline & & Temperature & ${ }^{\circ} \mathrm{C}$ \\
\hline & & Solar Radiation & $\mathrm{MJ} \cdot \mathrm{m}^{-2}$ \\
\hline & & Wind Direction & ${ }^{\circ}$ from True $\mathrm{N}$ \\
\hline & & Wind Speed & Knots \\
\hline \multirow{6}{*}{$\begin{array}{c}\text { Dependent } \\
\text { (Undesirable) } \\
\text { Output Variable }\end{array}$} & \multirow{6}{*}{$\begin{array}{l}\text { Environmental } \\
\text { pollution }\end{array}$} & $\mathrm{PM}_{2.5}$ pollution & $\mu \mathrm{g} / \mathrm{m}^{3}$ \\
\hline & & $\mathrm{PM}_{10}$ pollution & $\mu \mathrm{g} / \mathrm{m}^{3}$ \\
\hline & & $\mathrm{SO}_{2}$ pollution & $\mu \mathrm{g} / \mathrm{m}^{3}$ \\
\hline & & CO pollution & $\mu \mathrm{g} / \mathrm{m}^{3}$ \\
\hline & & $\mathrm{NO}_{2}$ pollution & $\mu \mathrm{g} / \mathrm{m}^{3}$ \\
\hline & & $\mathrm{O}_{3}$ pollution & $\mu \mathrm{g} / \mathrm{m}^{3}$ \\
\hline \multirow{2}{*}{$\begin{array}{c}\text { Dependent (Desirable) } \\
\text { Output Variable }\end{array}$} & Economic gains & Transport share of GCP & Ksh. \\
\hline & Wage situation & Average monthly wage & Ksh. \\
\hline
\end{tabular}

Important factors of principal components which showed major variance with transport-related parameters were then identified to be used as one of the outputs in the DEA model.

\subsubsection{Data Envelopment Analysis (DEA)}

The DEA model used was an input-oriented constant return to scale CRS DEA model in which the inputs are maximized and the outputs are kept at prior levels.

The model [57] was adopted as follows:

$$
\max \varnothing-\varepsilon\left(\sum_{i=1}^{m} s_{i}^{-}+\sum_{r=1}^{s} s_{r}^{+}\right)
$$

subject to

$$
\begin{gathered}
\sum_{j=1}^{n} \lambda_{j} x_{i j}+s_{i}^{-}=\theta x_{i o}, \quad i=1,2, \cdots, m ; \\
\sum_{j=1}^{n} \lambda_{j} y_{r j}-s_{i}^{+}=y_{r o}, \quad r=1,2, \cdots, s ; \\
\lambda_{j} \geq 0, \quad j=1,2, \cdots, n ;
\end{gathered}
$$

where DMUo represents one of the $n$ DMUs under evaluation, $x_{i o}$ and $y_{r o}$ are the $i$ th input and $t$ th output for $D M U o$, respectively.

\subsubsection{Multiple Linear Regression (MLR)}

Multiple linear regression was undertaken to identify the relationship that exists 
between transport eco-efficiency and various factors such as fuel consumption, amount of wages, traffic volume, number of employed persons, transport share of gross county product, and transport attributed principal component.

The formula for calculating multiple linear regression used was:

$$
y_{i}=\beta_{0}+\beta_{1} x_{i 1}+\beta_{2} x_{i 2}+\cdots+\beta_{p} x_{i p}+\epsilon
$$

where for $i=n$ observations: $y_{i}$ represents the dependent variable, $i$ is the explanatory variables, $\beta_{0}$ is the $y$-intercept or constant term, $\beta_{p}$ is the slope coefficients for each explanatory variable and $\epsilon$ is the model's error term.

\section{Results and Discussion}

\subsection{Source Apportionment by PCA}

Pearson correlation was undertaken to determine the strength and direction of the mean of the variables for all the 11 sub-counties. Rainfall (RN) and CO had the highest positive correlation with statistical significance ( $r=0.164, n=396, p$ $=0.005)$ while wind direction (WD) and ozone (O3) had the highest negative correlation with statistical significance $(r=-0.149, n=396, p=0.005)$. The $\mathrm{KMO}$ and Bartlett's test values were done before inputting the data for PCA. The data met the requirements that the Kaiser-Meyer-Olkin (KMO) of Sampling Adequacy be more significant than 0.50 for the arrangement of factors [58]. The values thus satisfied the requirements for PCA. All the parameters had an initial communality value of 1 . The communality values after extraction ranged from 0.125 to 0.976 for all parameters across all the sub-counties. The values below 0.5 were not adopted for the PCA. Twelve factors or components were initially identified but only five factors were utilized based on eigenvalues of each component before and after rotation for each sub-county. The mean resulting cumulative variability was $77.486 \%$ based on the five utilized factors. Factor 1 was more significant than factors 2, 3, 4 and 5 before and after rotation.

The classification and analysis of loading component were adopted as follows: any value greater than 0.5 is strong, any value between 0.4 and 0.49 is moderate and any value below 0.3 is weak [44]. In SPSS V23, the Extraction Method used was PCA while the Rotation Method used was Varimax with Kaiser Normalization. Loading component values under 0.4 were smothered from the yield. Principal component 1 mainly had positive contributions for traffic originated emissions from gasoline combustion by automobiles due to high loadings of $\mathrm{CO}$, $\mathrm{NO}_{2}$ and $\mathrm{SO}_{2}$ [59]. This principal component is strongly correlated and increases with increasing concentrations of $\mathrm{CO}, \mathrm{NO}_{2}$ and $\mathrm{SO}_{2}$. The negative principal component values were transformed to allow for compatibility with the DEA model chosen. The newly transformed values were used as one of the undesirable outputs in the model.

\subsection{Measurement of Eco-Efficiency with CRS DEA Model}

The study selected the Input-Oriented CRS Measure-Specific Efficiency for empirical analysis for months between June 2019 and May 2020 and the 11 
sub-counties of the city were chosen as Decision Making Units (DMUs). The mean transport eco-efficiency is less than 1.000 indicating that it is not at an optimal rate as shown in Figure 2. A low pollution state from the transport sector can be achieved by promoting low carbon development. The transport eco-efficiency of the city during the study period has a mean value of 0.67 suggesting that the transport share of the GCP and earnings from the sector have a potential to be increased by $33 \%$ if all the sub-counties improve the transport eco-efficiency all at one go. Transport eco-efficiency improved from June to August in 2019 and remained above the overall mean till December when it sharply deteriorated which is mainly attributed to a steady increase in PM concentration. It then improved steadily from December 2019 a keen to a light decrease in February 2020 before ultimately reaching the August 2019 level. This rebound resulted from decreased PM concentration levels despite a steady increase in the transport share of the GCP.

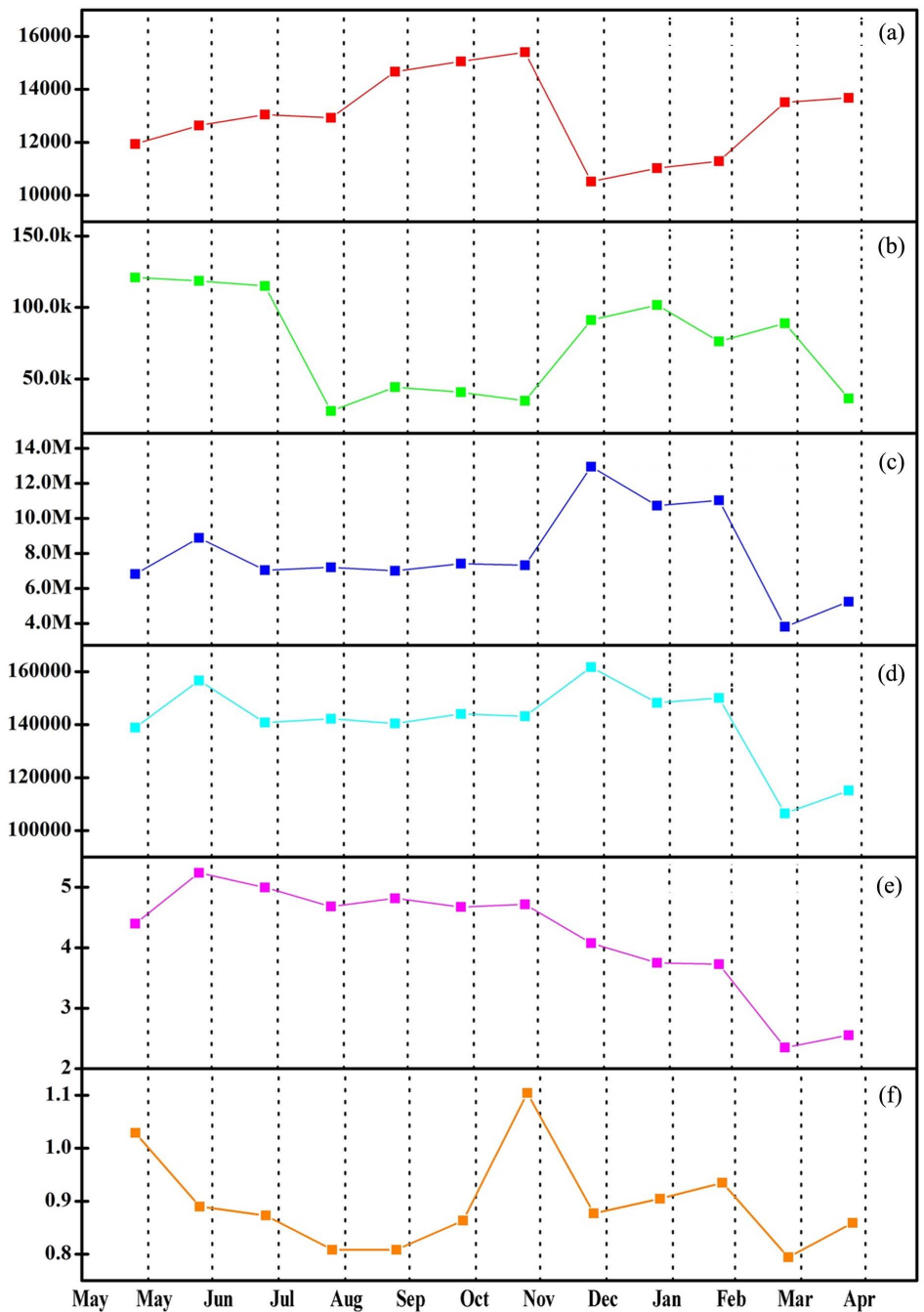

Figure 2. Time series of monthly values of various factors. (a) Transport share of GCP; (b) Number of employed; (c) Traffic volume; (d) Amount of wages; (e) Fuel consumption; (f) Transport eco-efficiency. 
Eco-efficiency being an instrument to measure the sustainability of economic activities [27] indicated that the Embakasi paid a high environmental price compared to Makadara from transport-related PM pollution. As shown in Figure 3, 4 out of the 11 DMUs are efficient at converting natural and social resources into economic output and environmental benefits [6]. These sub-counties showed better and higher transport eco-efficiency.

The specific results of transport-related air pollution for the 11 sub-counties are illustrated in Figure 4. The mean values of the eco-efficiency can be categorized into four kinds [9]:

1) Optimal efficiency (transport eco-efficiency $=1.000$ ) suggesting the most effective transport development;

2) High efficiency $(0.900 \leq$ transport eco-efficiency $<1.000)$ suggesting the transport development is in a good but not desired situation;

3) Medium efficiency $(0.500 \leq$ transport eco-efficiency $<0.900)$ suggesting the transport development is in an average situation; and

4) Poor efficiency (transport eco-efficiency < 0.500) suggesting the transport development is ineffective.

\subsection{Influence of Factors by Sub-Region on Transport Eco-Efficiency}

The multiple linear regression model was constructed as illustrated below. The dependent variable is transport eco-efficiency while the explanatory variables are the selective factors. The factors were normalized before SPSS V23 was used to extract the parameters for the model.

The model was:

$$
\begin{aligned}
T E E_{i t}= & -(0.0441) F C N-(0.469) W G S-(0.582) T R V \\
& +(0.319) E M T-(0.781) G C P-(1.082) T P C+0.631
\end{aligned}
$$

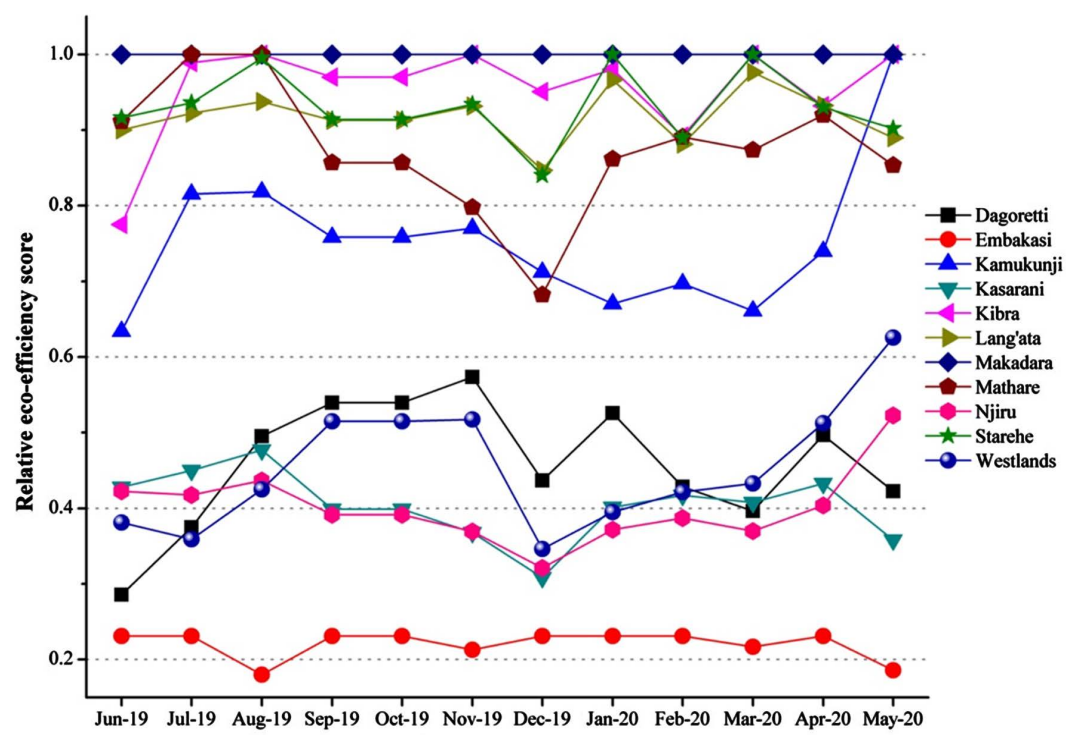

Figure 3. Relative transport eco-efficiency of each sub-county in Nairobi City. 

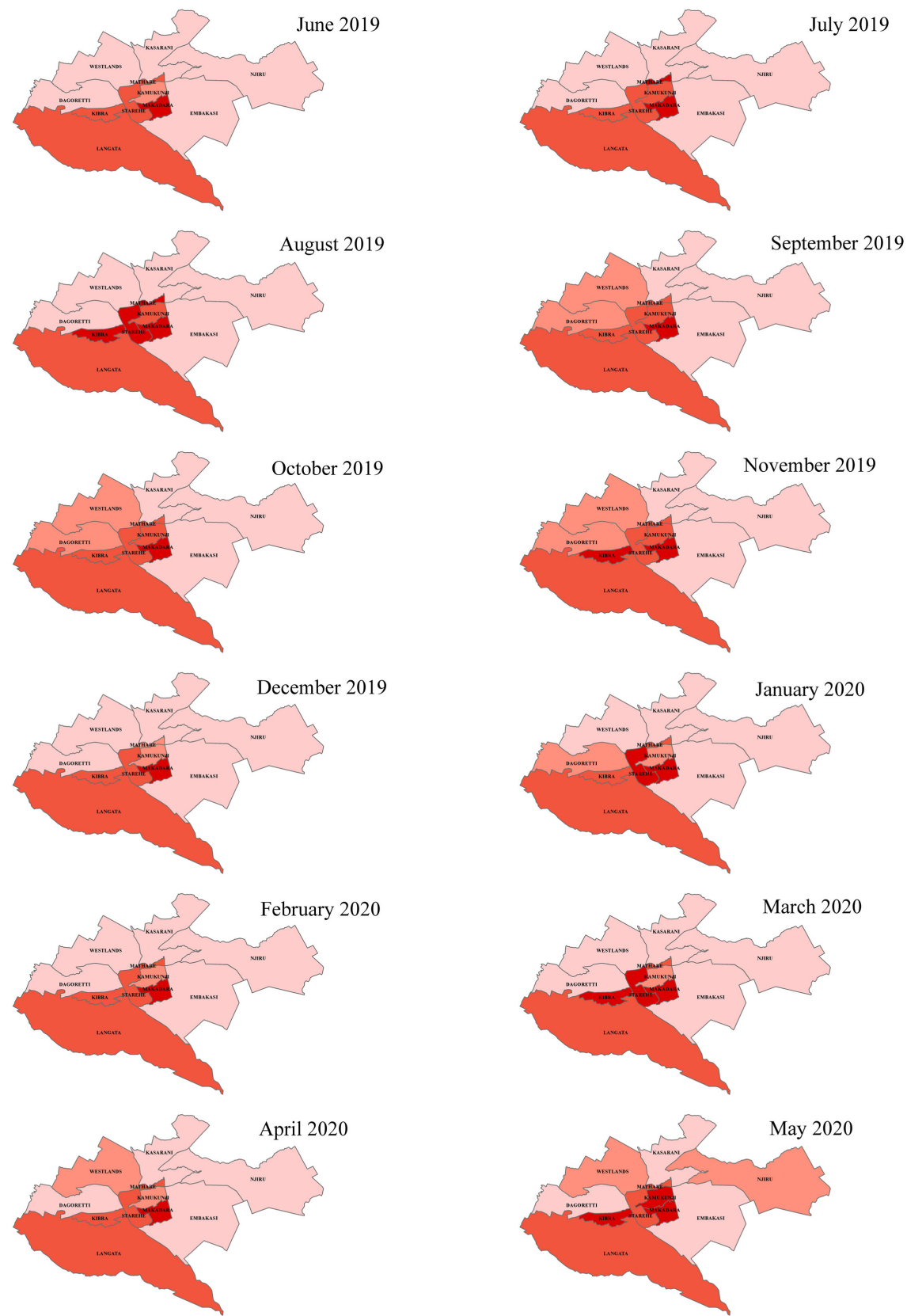

\section{Legend}

\begin{tabular}{|l|l}
$\square$ & $0.00-0.50$ \\
\hline & $0.75-0.99$ \\
\hline & $0.50-0.75$ \\
$\square$ & $0.99-1.00$
\end{tabular}

Figure 4. The spatial pattern of mean transport eco-efficiency of the 11 Nairobi sub-counties.

where $T E E$ is the transport eco-efficiency of sub-county $i$ in month $t, F C N$ is the fuel consumption, $W G S$ is the amount of wage, $T R V$ is the traffic volume, $E M T$ is the number of employed persons, $G C P$ is the transport share of gross county product and $T P C$ is the transport attributed principal component.

The results are explained below.

1) The fuel consumption ( $F C N)$ is key in determining transport eco-efficiency 
and has a negative influence on transport eco-efficiency with a significant negative relationship. Transport eco-efficiency will decrease by $44.1 \%$ with every $1 \%$ increase in fuel consumption. Thus, the higher the fuel consumption, the lower transport eco-efficiency will be.

2) The amount of wage (WGS) has a significant positive influence on transport eco-efficiency. For every 1\% increase in the number of wages, there is a consequential $46.9 \%$ increase in transport eco-efficiency. This suggests that the number of wages could significantly lead to the sustainable development of the transport sector in Nairobi City.

3) The traffic volume ( $T R V$ ) has an expected and significant negative influence on transport eco-efficiency. Transport eco-efficiency will decrease by $58.2 \%$ with every $1 \%$ increase in the traffic volume. This means that the more the vehicles with the existing characteristics are on the city roads, the lower the transport eco-efficiency will be.

4) The number of employed (EMT) has a significantly positive influence on transport eco-efficiency. For every $1 \%$ increase in the number of employed, there is a $31.9 \%$ increase in transport eco-efficiency. This means the more people are employed in the transport sector both formally or informally, the high the transport eco-efficiency will be.

5) The transport share of the $G C P$ has a significant negative influence on transport eco-efficiency. Transport eco-efficiency will decrease by $108.2 \%$ for every $1 \%$ increase in the transport share of the $G C P$. This suggests that more economic gains from the sector will translate into lower transport eco-efficiency hence more investment in the sector will not necessarily result in economic gains but an environmental improvement.

6) The transport attributed to PM pollution (TPC) has a significant negative influence on transport eco-efficiency. For every $1 \%$ increase in transport attributed to PM pollution, there is a $107 \%$ decrease in transport eco-efficiency. This suggests that the more the PM emissions, the more transport eco-efficiency will deteriorate.

\subsection{Influence of Factors by Vehicle Category on Transport Eco-Efficiency}

Transport eco-efficiency was noted to also be influenced by factors according to vehicle category. The factors considered were vehicle fleet numbers, fuel efficiency and carbon dioxide equivalent emissions. The accompanying Supplementary Information includes the vehicle fleet numbers, fuel consumption, fuel price variation, fuel efficiency and carbon dioxide equivalent in emissions. The multilinear regression models were constructed for buses (BS), heavy goods vehicles (HGV), light commercial vehicles (LCV), motorcycles (MC) and passenger cars (PC) as shown below. The dependent variable is transport eco-efficiency while the explanatory variables are vehicle fleet numbers, fuel efficiency and carbon dioxide equivalents.

The models were: 


$$
\begin{gathered}
T E E_{B S}=-(0.054) V F-(0.784) F E+(0.466) t C O 2 e+1.007 \\
T E E_{H G V}=-(0.008) V F-(0.784) F E+(0.479) t C O 2 e+0.853 \\
T E E_{L C V}=(0.017) V F-(1.058) F E+(0.767) t C O 2 e+0.873 \\
T E E_{M C}=-(0.366) V F-(0.526) F E-(0.177) t C O 2 e+0.988 \\
T E E_{P C}=-(0.054) V F-(0.784) F E+(0.466) t C O 2 e+1.145
\end{gathered}
$$

where $T E E_{B S}, T E E_{H G V}, T E E_{L C V}, T E E_{M C}$ and $T E E_{P C}$ is the transport eco-efficiency of each respective vehicle category in month $t, V F$ is the vehicle fleet numbers, $F E$ is the fuel efficiency and $t C O 2 e$ is the metric tons of Carbon Dioxide Equivalent.

The results are explained below.

1) Vehicle fleets $(V F)$ numbers generally have a negative influence on transport eco-efficiency. Transport eco-efficiency will decrease by $5.4 \%, 0.8 \%, 36.6 \%$ and $5.4 \%$ for every $1 \%$ increase in vehicle fleet heavy-duty vehicles, motorcycles and passenger cars respectively. Transport eco-efficiency will increase by $1.7 \%$ for every $1 \%$ increase in vehicle fleet numbers of light commercial vehicles. Thus, the higher the vehicle fleet numbers, the lower the transport eco-efficiency.

2) Fuel efficiency $(F E)$ of all the vehicle categories have a negative influence on transport eco-efficiency. Transport eco-efficiency will decrease by $78.4 \%, 77.3 \%$, $105.8 \%, 52.6 \%$ and $78.4 \%$ for every $1 \%$ increase in fuel efficiency of buses, heavy goods vehicles, light commercial vehicles, motorcycles and passenger cars respectively. Thus, the higher the fuel efficiency, the lower the transport eco-efficiency.

3) Carbon dioxide equivalent in emissions ( $t C O 2 e$ ) generally has a positive influence on transport eco-efficiency. Transport eco-efficiency will increase by $46.6 \%, 47.9 \%, 76.7 \%$ and $46.6 \%$ for every $1 \%$ increase in carbon dioxide equivalent emissions from buses, heavy goods vehicles, light commercial vehicles and passenger cars respectively. Transport eco-efficiency will decrease by $17.7 \%$ for every $1 \%$ increase in carbon dioxide equivalent emissions from motorcycles. Thus, the lower the carbon dioxide equivalent in emissions, the higher the transport eco-efficiency.

\section{Conclusions and Recommendations}

This study aimed to understand the eco-efficiency of transport-related air pollution from particulate matter by choosing and considering only transport affiliated input and output indicators. This was adequately achieved by an exploration of a combined PCA-DEA-MLR ${ }^{2}$ model approach which despite being rough is eventually well suited. An empirical inquiry was undertaken to understand the eco-efficiency of transport-related air PM pollution based on recent statistical data of Nairobi City and its 11 sub-counties from June 2019 to May 2020. This study contributes by constructing a PCA, DEA and MLR approach that was used to rank the transport eco-efficiency of various DMUs (sub-regions/sub-counties ${ }^{2}$ PCA stands for Principal Component Analysis, DEA stands for Data Envelopment Analysis and MLR stands for Multi Linear Regression. 
of the city). The data utilized were acquired from various databases, publications and reports, mostly from the Kenya National Bureau of Statistics, Sensors of Africa and the Central Bank of Kenya. The analysis was conducted based on panel data of Nairobi City to monitor changes over time. The output from this chosen methodology may help guide transport policymaking by assessing quantitatively the implications of environmental management from the angle of transportation.

The results from the study reveal that the transport eco-efficiency in the city is generally low. The transport eco-efficiency in only one out of the 11 sub-counties was in an effective or optimum situation with the rest having a lot of possibilities for improvement. Transport eco-efficiency varied considerably between the sub-counties. The efficiency values in Makadara, Kibra and Lang'ata sub-counties were generally high; those of Kamukunji and Mathare were broadly medium while those of Embakasi, Njiru, Kasarani, Westlands and Dagoretti were low. Concerning the overall factors affecting transport eco-efficiency, amount of wages and number of employed had a noteworthy positive impact on transport eco-efficiency while fuel consumption, traffic volume, transport share of the GCP and transport attributed PM pollution had a notable negative impact on transport eco-efficiency. Regarding the factors by vehicle category that affect transport eco-efficiency, vehicle fleet numbers and fuel efficiency had noteworthy negative impacts on transport eco-efficiency while carbon dioxide equivalent in emissions had a notable negative impact on transport eco-efficiency. As a consequence of the overall state of transport eco-efficiency and the transport sector in Nairobi City and its sub-counties, particular steps can be put into consideration to make improvements.

Sub-counties to the north (Kasarani), east (Embakasi and Njiru) and west (Westlands) parts of the city should be targeted with steady and sustainable transport development directions due to their lower transport eco-efficiency compared to the rest of the city. Apt and intensified management of the transport activities should be strived at through stakeholder engagement and public awareness of the benefits of achieving optimum transport eco-efficiency. Still, it will be crucial to ensure that localized strategies of transport development should be aligned within the city and national plans/visions of improving the state of the environment. The transport sector should also be revamped and modernized to reduce informality while focusing on formalization for improved wages, revenues and the environment alike. Such efforts should be coordinated and structured by factoring in functions and contributions from existing government institutions such as the National Environmental Management Authority, the Kenya Urban Roads Authority, the Kenya National Highways Authority.

Considerable efforts should be made towards the integrated development of the transport sector in the city to enhance the eco-efficiency thus the sustainability of the sector. The National Government and County Government of Nairobi should pay particular attention to the emerging need to address the particulate matter pollution that results from the transport sector with an emphasis on mass 
transportation in the city to balance the economic development of the sector and environmental protection. Principally, sub-counties with medium to low transport eco-efficiency should be targeted for enhancement of the transport eco-efficiency. Policies and regulations with funding mechanisms should be established to aid in shifting the transport sector from a high pollution contributor to a low-carbon and high-efficiency state. With this, the transport sector will have a high potential of providing the city residents with a healthy living environment while economically benefitting the actors and the general public. A potential extension of this study is to evaluate the eco-efficiency of transport-related particulate matter in other cities in Kenya to provide a platform for comparisons and insights. Such will aid in countrywide integration of localized efforts of environmental management through the transport sector which is a high impact sector of the regional and national economy.

\section{Acknowledgements}

The authors would like to thank the reviewers for their valuable and useful comments on the manuscript. All errors and omissions remain ours.

\section{Conflicts of Interest}

The authors declare that there exists no conflict of interest.

\section{References}

[1] Raje, F., Tight, M. and Pope, F.D. (2018) Traffic Pollution: A Search for Solutions for a City like Nairobi. Cities, 82, 100-107. https://doi.org/10.1016/j.cities.2018.05.008

[2] Gaita, S.M., Gatari, M.J., Pettersson, J.B.C. and Janhäll, S. (2014) Source Apportionment and Seasonal Variation of $\mathrm{PM}_{2.5}$ in a Sub-Saharan African City: Nairobi, Kenya. Atmospheric Chemistry and Physics, 14, 9977-9991. https://doi.org/10.5194/acp-14-9977-2014

[3] Gichuru, M., et al. (2017) High Airborne Black Carbon Concentrations Measured near Roadways in Nairobi, Kenya. Transportation Research Part D: Transport and Environment, 68, 99-109.

[4] Mbandi, A.M., et al. (2019) Estimating On-Road Vehicle Fuel Economy in Africa: A Case Study Based on an Urban Transport Survey in Nairobi, Kenya. Energies, 12, 1177. https://doi.org/10.3390/en12061177

[5] UNEP (2020) Used Vehicles and the Environment: A Global Overview of Used Light Duty Vehicles: Flow Scale and Regulation. United Nations Environment Programme, Nairobi.

[6] Fan, Y.P., Qiao, Q., Kang, P., Zhang, Y. and Guo, J. (2017) Study on Eco-Efficiency of Industrial Parks in China Based on Data Envelopment Analysis. Environmental Management, 192, 107-115. https://doi.org/10.1016/j.jenvman.2017.01.048

[7] Song, Y., Liang, S.B., et al. (2018) Research on Industrial Eco-Efficiency Evaluation of Capital Cities in China. Ekoloji, 27, 1377-1385.

[8] Yu, C., de Jong, M., Shi, H., et al. (2015) From an Eco-Industrial Park towards an Eco-City: A Case Study in Suzhou, China. Journal of Cleaner Production, 102, 264-274. https://doi.org/10.1016/j.jclepro.2015.04.021 
[9] Liu, J., Fu, Z.B., et al. (2017) Tourism Eco-Efficiency of Chinese Coastal Cities-Analysis Based on the DEA-Tobit Model. Ocean \& Coastal Management, 148, 164-170. https://doi.org/10.1016/j.ocecoaman.2017.08.003

[10] Suh, S., Ha, S.S., et al. (2005) Eco-Efficiency for Pollution a Prevention in Small to Medium-Sized Enterprises: A Case from South Korea. Journal of Industrial Ecology, 9, 223-240. https://doi.org/10.1162/108819805775247918

[11] Bohne, R.A., Bergsdal, H., et al. (2008) Dynamic Eco-Efficiency Projections for Construction and Demolition Waste Recycling Strategies at the City Level. Journal of Industrial Ecology, 12, 52-68. https://doi.org/10.1111/j.1530-9290.2008.00013.x

[12] Lam, C.-M., Hsu, S.-C., et al. (2016) Eco-Efficiency Analysis of Sludge Treatment Scenarios in Urban Cities: The Case of Hong Kong. Journal of Cleaner Production, 112, 3028-3039. https://doi.org/10.1016/j.jclepro.2015.10.125

[13] Ren, Y.F., Lin, X.Q., Sun, S., Li, G.D., Fan, B.L., et al. (2019) Evaluation of the Eco-Efficiency of Four Major Urban Agglomerations in Coastal Eastern China. Journal of Geographical Sciences, 29, 1315-1330. https://doi.org/10.1007/s11442-019-1661-7

[14] Huang, Y., Yu, Y.T., et al. (2018) Does Urban Cluster Promote the Increase of Urban Eco-Efficiency? Evidence from Chinese Cities. Journal of Cleaner Production, 197, 1307-1316. https://doi.org/10.1016/j.jclepro.2018.06.251

[15] Li, Z., Du, K.R., Zhao, Y., et al. (2017) Does Government Transparency Contribute to Improved Eco-Efficiency Performance? An Empirical Study of 262 Cities in China. Energy Policy, 110, 79-89. https://doi.org/10.1016/j.enpol.2017.08.001

[16] Li, D.Z., Leung, B.Y.P., Li, X.M., Xing, X., et al. (2010) A Methodology for Eco-Efficiency Evaluation of Residential Development at City Level. Building and Environment, 45, 566-573. https://doi.org/10.1016/j.buildenv.2009.07.012

[17] Beltrán-Esteve, M. and Picazo-Tadeo, A.J. (2015) Assessing Environmental Performance Trends in the Transport Industry: Eco-Innovation or Catching-Up? Energy Economics, 51, 570-580. https://doi.org/10.1016/j.eneco.2015.08.018

[18] Park, Y.S., et al. (2018) Environmental Efficiency Assessment of US Transport Sector: A Slack-Based Data Envelopment Analysis Approach. Transportation Research Part D Transport and Environment, 61, 152-164. https://doi.org/10.1016/j.trd.2016.09.009

[19] Chen, X., et al. (2020) Assessing Eco-Performance of Transport Sector: Approach Framework, Static Efficiency and Dynamic Evolution. Transportation Research Part D: Transport and Environment, 85, Article ID: 102414.

https://doi.org/10.1016/j.trd.2020.102414

[20] Iqbal, A., Afroze, S., et al. (2017) Analysis of Transport Eco-Efficiency Scenarios to Support Sustainability Assessment: A Study on Dhaka City, Bangladesh. Environmental Monitoring and Assessment, 189, 366. https://doi.org/10.1007/s10661-017-6078-0

[21] Song, S. (2018) Assessment of Transport Emissions Impact and the Associated Social Cost for Chengdu, China. International Journal of Sustainable Transportation, 12, 128-139. https://doi.org/10.1080/15568318.2017.1337833

[22] van Zanten, H.H.E., Mollenhorst, H., Klootwijk, C.W., van Middelaar, C.E. and de Boer, I.J.M. (2015) Global Food Supply: Land Use Efficiency of Livestock Systems. The International Journal of Life Cycle Assessment, 21, 747-758. https://doi.org/10.1007/s11367-015-0944-1

[23] Beames, A., Heijungs, R., Lookman, R., Boonen, K., Van Geert, Y., Dendoncker, K., Seuntjens, P., et al. (2015) Accounting for Land-Use Efficiency and Temporal Vari- 
ations between Brownfield Remediation Alternatives in Life-Cycle Assessment. Journal of Cleaner Production, 101, 109-117. https://doi.org/10.1016/j.jclepro.2015.03.073

[24] Meng, Y., An, P.-L., Dong, M.-L., Wang, Z.-Y., Zhao, T.T., et al. (2007) Industrial Land-Use Efficiency and Planning in Shunyi, Beijing. Landscape and Urban Planning, 85, 40-48.

[25] Vogtländer, J., Brezet, H., et al. (2002) Communicating the Eco-Efficiency of Products and Services by Means of the Eco-Costs/Value Model. Journal of Cleaner Production, 10, 57-67. https://doi.org/10.1016/S0959-6526(01)00013-0

[26] Wang, Y.T., Hansson, L., Zhang, K., Wang, R.Q., et al. (2011) Implementing Stricter Environmental Regulation to Enhance Eco-Efficiency and Sustainability: A Case Study of Shandong Province's Pulp and Paper Industry, China. Journal of Cleaner Production, 19, 303-310. https://doi.org/10.1016/j.jclepro.2010.11.006

[27] Liu, Y., Li, X.Q., Zhang, G.Q., et al. (2010) Eco-Efficiency of Urban Material Metabolism: A Case Study in Xiamen, China. International Journal of Sustainable Development \& World Ecology, 17, 142-148.

https://doi.org/10.1080/13504501003603223

[28] Cerutti, A., Bagliani, M., Donno, D., Bounous, G., et al. (2013) Multifunctional Ecological Footprint Analysis for Assessing Eco-Efficiency: A Case Study of Fruit Production Systems in Northern Italy. Journal of Cleaner Production, 40, 108-117. https://doi.org/10.1016/j.jclepro.2012.09.028

[29] Lenzen, M., et al. (2001) A Modified Ecological Footprint Method and Its Application to Australia. Ecological Economics, 37, 229-255.

https://doi.org/10.1016/S0921-8009(00)00275-5

[30] Barath, L. and Ferto, I. (2015) Heterogeneous Technology, Scale of Land Use and Technical Efficiency: The Case of Hungarian Crop Farms. Land Use Policy, 42, 141-150. https://doi.org/10.1016/j.landusepol.2014.07.015

[31] Robaina-Alves, M., Moutinho, V. and Macedo, P. (2015) A New Frontier Approach to Model the Eco-Efficiency in European Countries. Journal of Cleaner Production, 103, 562-573. https://doi.org/10.1016/j.jclepro.2015.01.038

[32] Tone, K. (2001) A Slacks-Based Measure of Efficiency in Data Envelopment Analysis. European Journal of Operational Research, 130, 498-509.

https://doi.org/10.1016/S0377-2217(99)00407-5

[33] Lin, J.Y., Wang, W., Cui, S.H., Wei, X.H., et al. (2010) An Eco-Efficiency-Based Urban Sustainability Assessment Method and Its Application. International Journal of Sustainable Development \& World Ecology, 17, 356-361. https://doi.org/10.1080/13504509.2010.493070

[34] Yin, K., An, Q.X., Yao, L., Liang, J., et al. (2014) Using Eco-Efficiency as an Indicator for Sustainable Urban Development: A Case Study of Chinese Provincial Capital Cities. Ecological Indicators, 36, 665-671. https://doi.org/10.1016/j.ecolind.2013.09.003

[35] Yu, Y., Huang, J. and Zhang, N. (2019) Modeling the Eco-Efficiency of Chinese Prefecture-Level Cities with Regional Heterogeneities: A Comparative Perspective. Ecological Modelling, 402, 1-17. https://doi.org/10.1016/j.ecolmodel.2019.03.012

[36] Ji, X., Zhu, Q.Y., Sun, J.S., et al. (2019) Using a Hybrid Heterogeneous DEA Method to Benchmark China's Sustainable Urbanization: An Empirical Study. Annals of Operations Research, 278, 281-335. https://doi.org/10.1007/s10479-018-2855-6

[37] Huang, J.H., et al. (2019) Eco-Efficiency Convergence and Green Urban Growth in 
China. International Regional Science Review, 42, 307-334. https://doi.org/10.1177/0160017618790032

[38] Zhou, J.G., et al. (2016) Provincial Eco-Efficiency Research in Eastern China Based on Super Efficiency DEA and Malmquist Index. 2016 3rd International Conference on Economic, Business Management and Educational Innovation (Ebmei 2016), Prague, Czech Republic, 10-11 May 2016, 5.

[39] Chen, J.H., et al. (2016) Operational Efficiency Evaluation of Iron Ore Logistics at the Ports of Bohai Bay in China: Based on the PCA-DEA Model. Mathematical Problems in Engineering, 2016, Article ID: 9604819. https://doi.org/10.1155/2016/9604819

[40] McNabola, A., Broderick, B.M. and Gill, L.W. (2009) A Principal Components Analysis of the Factors Effecting Personal Exposure to Air Pollution in Urban Commuters in Dublin, Ireland. Environmental Science and Health Part A-Toxic/Hazardous Substances \& Environmental Engineering, 44, 1219-1226. https://doi.org/10.1080/10934520903139928

[41] Ahmad, M., et al. (2020) Chemical and Source Characterization of $\mathrm{PM}_{2.5}$ in Summertime in Severely Polluted Lahore, Pakistan. Atmospheric Research, 234, Article ID: 104715. https://doi.org/10.1016/j.atmosres.2019.104715

[42] Azid, A., et al. (2014) Prediction of the Level of Air Pollution Using Principal Component Analysis and Artificial Neural Network Techniques: A Case Study in Malaysia. Water Air and Soil Pollution, 225, 2063. https://doi.org/10.1007/s11270-014-2063-1

[43] Li, W., et al. (2012) Eco-Efficiency of Manufacturing Processes: A Grinding Case. CIRP Annals, 61, 59-62. https://doi.org/10.1016/j.cirp.2012.03.029

[44] Abdul-wahab, S., Bakheit, C. and Al-Alawi, S. (2005) Principal Component and Multiple Regression Analysis in Modelling of Ground-Level Ozone and Factors Affecting Its Concentrations. Environmental Modelling \& Software, 20, 1263-1271. https://doi.org/10.1016/j.envsoft.2004.09.001

[45] KNBS (2019) Kenya Population and Housing Census Volume I: Population by County and Sub-County. Kenya National Bureau of Statistics, Nairobi.

[46] ESCAP (2009) Eco-Efficiency Indicators: Measuring Resource-Use Efficiency and the Impact of Economic Activities on the Environment. United Nations Economic and Social Commission for Asia and the Pacific.

https://www.unescap.org/sites/default/files/publications/eco\%20efficiency\%20indic ators\%202009.pdf

[47] Code-for-Africa (2020) Sensors. AFRICA Air Quality Archive Nairobi. Nairobi.

[48] MIT-Senseable-City-Lab (2018) Clean Air Nairobi. MIT-Senseable-City-Lab.

[49] OpenAQ/US-EPA (2018) Air Quality Data. OpenAQ.

[50] Kenya-Meteorological-Department (2020) Mean Daily Meteorological Data. Kenya Meteorological Department.

[51] Kenya-National-Bureau-of-Statistics (2020) Statistical Releases, in Quarterly GDP Reports. Kenya-National-Bureau-of-Statistics.

[52] Central-Bank-of-Kenya (2020) Monthly Economic Indicators. Central-Bank-of-Kenya.

[53] Nairobi-City-County (2014) Nairobi Integrated Urban Development Master Plan. Nairobi-City-County, Nairobi.

[54] Poldaru, R. and Roots, J. (2014) A PCA-DEA Approach to Measure the Quality of Life in Estonian Counties. Socio-Economic Planning Sciences, 48, 65-73.

https://doi.org/10.1016/j.seps.2013.10.001 
[55] António Afonso, S.F. (2008) Assessing and Explaining the Relative Efficiency of Local Government. Socio-Economics, 37, 1946-1979.

https://doi.org/10.1016/j.socec.2007.03.007

[56] Lars Otto, P.B. (2010) Benchmarking with DEA, SFA, and R. International Series in Operations Research \& Management Science, Vol. 157, Springer Science \& Business Media, Berlin.

[57] Zhu, J. (2014) Quantitative Models for Performance Evaluation and Benchmarking: Data Envelopment Analysis with Spreadsheets. 3rd Edition, International Series in Operations Research \& Management Science, Vol. 213, Springer, Berlin.

[58] Abdullah, S. and Ismail, M. (2018) Identification of Air Pollution Potential Sources through Principal Component Analysis (PCA). International Journal of Civil Engineering and Technology, 9, 1435-1442.

[59] Papamanolis, N. (2015) The Main Characteristics of the Urban Climate and the Air Quality in Greek Cities. Urban Climate, 12, 49-64.

https://doi.org/10.1016/j.uclim.2014.11.003 